\title{
ABSOLUTE STANDARDS FOR CLIMATE MEASUREMENTS
}

\author{
J. Leckey ${ }^{\mathrm{a}, *}$

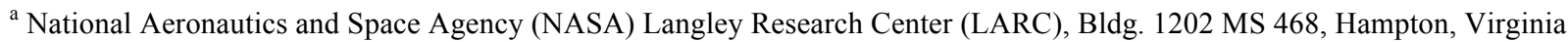 \\ 23681 USA - john.p.leckey@nasa.gov
}

Commission VIII, WG III/3

KEY WORDS: Infrared, Far-Infrared, Radiance, Climate, Atmosphere, Standard, SI Traceable, Measurement

\begin{abstract}
:
In a world of changing climate, political uncertainty, and ever-changing budgets, the benefit of measurements traceable to SI standards increases by the day. To truly resolve climate change trends on a decadal time scale, on-orbit measurements need to be referenced to something that is both absolute and unchanging. One such mission is the Climate Absolute Radiance and Refractivity Observatory (CLARREO) that will measure a variety of climate variables with an unprecedented accuracy to definitively quantify climate change. In the CLARREO mission, we will utilize phase change cells in which a material is melted to calibrate the temperature of a blackbody that can then be observed by a spectrometer. A material's melting point is an unchanging physical constant that, through a series of transfers, can ultimately calibrate a spectrometer on an absolute scale. CLARREO consists of two primary instruments: an infrared (IR) spectrometer and a reflected solar (RS) spectrometer. The mission will contain orbiting radiometers with sufficient accuracy to calibrate other space-based instrumentation and thus transferring the absolute traceability. The status of various mission options will be presented.
\end{abstract}

\section{INTRODUCTION}

According to the Intergovernmental Panel on Climate Change (IPCC) - "Each of the last three decades has been successively warmer at the Earth's surface than any preceding decade since 1850. The period from 1983 to 2012 was likely the warmest 30year period of the last 1400 years in the Northern Hemisphere" (IPCC 2013). Measuring climate change on a decadal time scale is vital to understanding model accuracy and properly attributing climate change to its source (IPCC 2012). While crucial, the small decadal scale signals of climate change are quite small compared to short-term natural variability; therefore, remain elusive to the majority of current global satellites. The Climate Absolute Radiance and Refractivity Observatory (CLARREO) mission seeks to improve the absolute accuracy of climate change measurements by bringing SI traceable standards on-orbit.

\section{CLIMATE ABSOLUTE RADIANCE AND REFRACTIVITY OBSERVATORY (CLARREO)}

The National Research Council (NRC) Decadal Survey on Earth Science and Applications from Space (2007) identified the uncertainties present in climate variables as a major problem for climate policymaking and risk management. The NRC also identified the need to make measurements with sufficient accuracy to resolve small climate change signals over decadal time scales (NRC 2007). One of the primary challenges of any space-borne instrument is the uncertainty in calibration over long time scales. CLARREO will address this challenge by carrying an absolute calibration standard onto orbit. The requirements of CLARREO are driven by long-term absolute accuracy rather than the usual approach of instantaneous noise requirements.

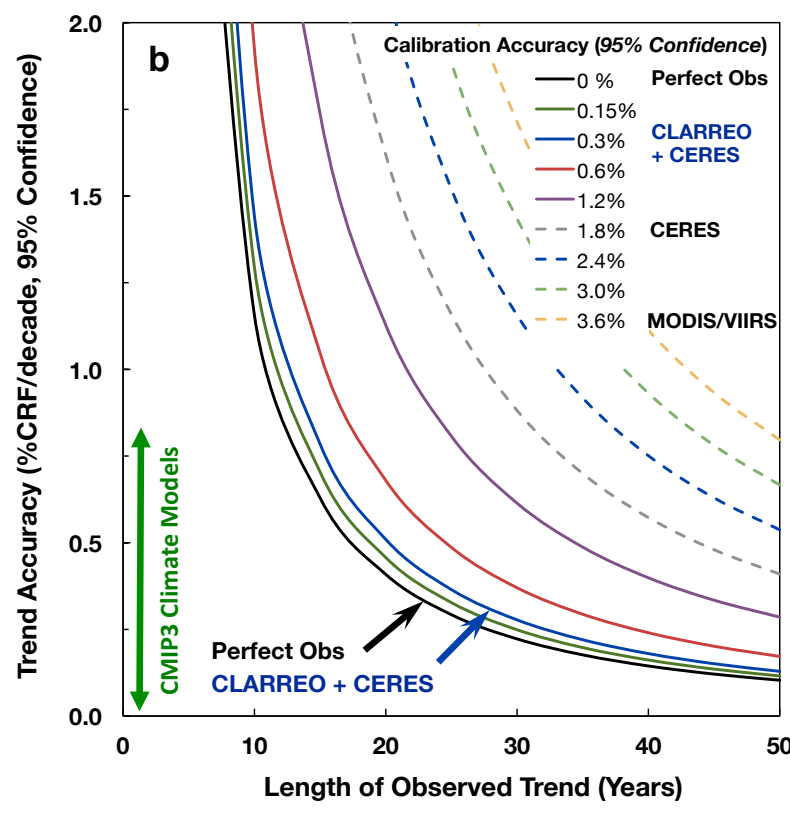

Figure 1. Accuracy of current earth observing missions and the potential improvement by CLARREO (Wielicki 2013)

Figure 1 shows the accuracy trend of cloud radiative forcing per decade as a function of the length of the observed trend. Current missions are shown and include CERES and MODIS/VIIRS, where it is clear that the length of time necessary to reach $1 \%$ accuracy in cloud radiative forcing is 30 years with current instruments alone. The time to detect a trend is reduced by nearly 20 years with the addition of an instrument of CLARREO's accuracy levels (Wielicki 2013).

\footnotetext{
* Corresponding author.
} 
The primary CLARREO measurements as defined in the NRC Decadal Survey are spectrally resolved infrared (IR) radiance emitted from Earth to space and spectrally resolved nadir reflected solar (RS) radiation. The measurements were strategically chosen to resolve the least understood climate forcings. The primary climate variable targets are: the atmospheric distribution of temperature and water vapor, broadband emitted radiative fluxes, temperature, emissivity, and cloud properties for the IR; and the atmospheric distribution of temperature and water vapor, broadband reflected radiative fluxes, surface albedo, and cloud properties for the RS. In combination with other measurements, the CLARREO data will resolve the rate at which climate change is occurring, improve future climate modeling, and improve the absolute accuracy of both currently orbiting weather and climate satellites through absolute reference calibrations on orbit. CLARREO will intercalibrate other sensors by transferring its calibration through simultaneous measurements of overlapping fields of view.

The CLARREO Infrared Spectrometer is a $5 \mu \mathrm{m}-50 \mu \mathrm{m}$ Fourier transform spectrometer (FTS). The strength of the IR spectrometer is its SI-traceable verification standards that are launched with the spectrometer. Earth observing missions carefully calibrate their sensors before launch and assume that nothing changes during launch and deployment of the instrument. In addition, traditional instruments also need mission overlaps where an aging sensor can be cross-calibrated with a newly launched sensor. Alternatively, CLARREO will not only undergo careful calibration before launch, but will undergo regular on-orbit re-calibrations using the onboard standards.

The CLARREO IR instrument contains 2 blackbodies. One is unique because of two key features: a heated baffle surrounding the entrances of the blackbodies and phase change cells. When correctly aligned, the view of a blackbody is purely from deep within the blackbody and not from the edges or other components. The heated baffle emits radiation and as long as the view of the blackbody is pure, there will be no additional signal. If an additional signal is seen, a correction is necessary. The phase change cells contain three different pure elements that melt/solidify at temperatures that span the operating points of the blackbodies. During a calibration, the blackbody is heated and the material undergoes a phase transition; the temperature versus time curve flattens while the material is melting and then resumes increasing once the material melts. The three element melt points provide three absolute, SItraceable, temperature measurements to fix the temperature sensors of the blackbody to an absolute scale. While a temperature probe's calibration may drift with time, elemental melt points do not and thus the temperature probes inside the blackbody will be absolutely calibrated with every material melt (Wielicki 2013).

The Reflected Solar (RS) spectrometer is a grating spectrometer from $320 \mathrm{~nm}-2300 \mathrm{~nm}$ with $4 \mathrm{~nm}$ spectral sampling and the goal of less than $0.3 \%$ calibration uncertainty. The absolute accuracy requirement is nearly an order of magnitude better than any comparable instrument. The spectrometer observes the Earth's surface and measures radiance that can be converted to reflectance by making similar lunar and solar measurements. A radio is then used to remove offsets with geometrical effects removed. The different measurements are especially difficult to make because the signals can vary by orders of magnitude between the brightest (solar) and dimmest (lunar) signals. The RS spectral range was chosen so that the CLARREO instrument can intercalibrate CERES and VIIRS. The intercalibration will require that the RS instrument to have sufficient pointing accuracy as to precisely overlap the same field of view that is being measured by a different sensor.

In order to meet these accuracy standards, a rigorous calibration approach was needed. The RS instrument's calibration starts with a series of laboratory-based measurements that will be inputs to a sensor model. Prior to launch, radiance and irradiance modes will be thoroughly calibrated, including all of the appropriate geometrical measurements for a conversion to reflectance. After the instrument is on-orbit, pre-launch laboratory measurements in the sensor model will be compared to solar absolute irradiance measurements to demonstrate post launch accuracy and if any changes occurred, they will be incorporated into the model. Stellar and lunar measurements post-launch will also be incorporated into the sensor model so the model can evolve with time and still retain absolute accuracy. Once the model prediction matches the on-orbit measurements, the sensor will be fully calibrated. The solar and lunar measurements will track any temporal changes in the sensor over time once an initial model agreement takes place.

\section{SUMMARY}

In summary, we live in a world where there is an ever growing need to measure climate change as fast as possible. We are limited by natural variability, but with measurements focused on absolute accuracy and with on-orbit SI traceable calibration sources, climate variables can be resolved much faster than was previously possible. CLARREO is one such mission that will be able to measure climate change on the desired timescales.

\section{REFERENCES}

IPCC, 2007a: Climate Change 2007: "The Physical Science Basis," Contribution of Working Group I to the Fourth Assessment Report of the Intergovernmental Panel on Climate Change [Solomon, S., D. Qin, M. Manning, Z. Chen, M. Marquis, K.B. Averyt, M. Tignor and H.L. Miller (eds.)]. Cambridge University Press, Cambridge, United Kingdom and New York, NY, USA

IPCC, 2013: Climate Change 2013: "The Physical Science Basis", Contribution of Working Group I to the Fifth Assessment Report of the Intergovernmental Panel on Climate Change [Stocker, T.F., D. Qin, G.-K. Plattner, M. Tignor, S.K. Allen, J. Boschung, A. Nauels, Y. Xia, V. Bex and P.M. Midgley (eds.)]. Cambridge University Press, Cambridge, United Kingdom and New York, NY, USA, 1535

NRC, 2007: "Earth Science and Applications from Space: National Imperatives for the Next Decade and Beyond," The National Academy Press, 428

Wielicki, B.A., D.F. Young, M.G. Mlynczak, K.J. Thome, S. Leroy, J. Corliss, J.G. Anderson, C.O. Ao, R. Bantges, F. Best, K. Bowman, H. Brindley, J. Butler, W. Collins, J.A. Dykema, D.R. Doelling, D.R. Feldman, N. Fox, X. Huang, R. Holz, Y. Huang, Z. Jin, D. Jennings, D.G. Johnson, K. Jucks, S. Kato, D.B. Kirk-Davido, R. Knuteson, G. Kopp, D.P. Kratz, X. Liu, C. Lukashin, A.J. Mannucci, N. Phojanamongkolkij, P. Pilewskie, V. Ramaswamy, H. Revercomb, J. Rice, Y. Roberts, C.M. Roithmayr, F. Rose, S. Sandford, E.L. Shirley, W.L. Smith, Sr., B. Soden, P.W. Speth, W. Sun, P.C. Taylor, D. Tobin, X. Xiong, 2013: "Achieving Climate Change Absolute Accuracy in Orbit” Bull. Amer. Meteor. Soc., pp 1519 - 1539 